\title{
Mates of Competitive Females: The Relationships between Female Aggression, Mate Quality, and Parental Care
}

\author{
Kristal E. Cain \\ Evolution, Ecology \& Genetics, Research School of Biology, The Australian National University, Acton, ACT 0200, Australia \\ Correspondence should be addressed to Kristal E. Cain; kristalcain@gmail.com
}

Received 17 April 2014; Revised 9 June 2014; Accepted 10 June 2014; Published 30 June 2014

Academic Editor: Luciano J. Avila

Copyright ( 2014 Kristal E. Cain. This is an open access article distributed under the Creative Commons Attribution License, which permits unrestricted use, distribution, and reproduction in any medium, provided the original work is properly cited.

\begin{abstract}
Though rarely mate-limited, females in a wide variety of species express traits commonly associated with mate competition in males. Recent research has shown that these competitive traits (ornaments, armaments, and intense aggression) often function in the context of female-female competition for nonsexual reproductive resources and are often positively related to reproductive success. Increased success could occur because competitive females acquire limited ecological resources (nest sites, territories, etc.) or because they pair with high quality males, that is, older, more ornamented, or more parental males. Further, males paired with aggressive/low care females may compensate by increasing their paternal efforts. Here, I examined patterns of social pairing and parental care in free-living dark-eyed juncos (Junco hyemalis), a biparental songbird. I found no detectable relationship between female competitive behavior (aggression) and male quality (age, size, or ornamentation) or male provisioning. Thus, neither of the mate choice hypotheses (females compete for males or males prefer aggressive females) was supported. Instead, these results suggest that females compete for nonsexual resources and mate quality is a secondary consideration. I also found a negative relationship between male and female provisioning rates, suggesting that partners adjust their level of parental effort in response to their partner's efforts.
\end{abstract}

\section{Introduction}

Though females are rarely mate-limited, they are often limited by access to other important reproductive resources such as territories, ovoposition sites, and dominance rank [1-6]. Social selection argues that competition for any important resource, sexual or nonsexual, can lead to the evolution of ornaments, armaments, intense aggression, or complex acoustic signals, hereafter referred to as competitive traits $[1,2]$. Recent empirical work examining the functional consequences of female expression of competitive traits supports the predictions of social selection; females with greater degree of trait expression often have improved reproductive success $[1,2,4,6,7]$. This pattern is particularly interesting because in many vertebrates increased trait expression is also associated with a reduction in some forms of maternal care [8-13]. A positive relationship between trait expression and reproductive success might emerge because, as social selection would predict, competitive females are more likely to acquire high quality mates or other limited reproductive resources. However, an alternative explanation is that males differentially invest in females with greater trait expression, either via mate preferences or by investing more in the female and her offspring (e.g., nuptial gifts, offspring feeding, and nest defense). Most research to date has focused on testing only one of the two possibilities. In order to develop a better understanding of the selective forces mediating female competitive traits expression we need to examine both simultaneously.

Female-female aggression is a ubiquitous competitive trait, which is positively related to reproductive success in a number of species $[3,4,11,14]$. Evidence suggests that more aggressive females are more likely to acquire resources important for breeding, such as a nesting cavity [15], dominance [16, 17], or breeding status [18-21], suggesting that female-female competition for resources is a primary reason that more aggressive females experience greater success. However, males, particularly socially monogamous and biparental males, may mediate the relative costs and benefits that females experience from heightened aggression 
in a number of ways that are not mutually exclusive [22]. For instance, aggressive females might have higher quality males, that is, mates that provide greater direct (material) or indirect (genetic) benefits. This pattern could be the result of females competing directly for males or males preferring aggressive females. In either scenario, aggressive females might have greater success because, to some extent, they have a better social mate. Greater reproductive success of aggressive females could also be the result of males investing more heavily in offspring care when mated to aggressive females. For example, if males perceived aggressive females to be of higher quality, that is, have greater access to limited resources or higher breeding status, they may invest more in that reproductive attempt. Greater male care could also emerge if aggressive females invest less in some forms of maternal care $[8,11,23]$ and males act to compensate for this reduction. Finally, males may simply adjust their care level to female efforts, rather than using any perceived measure of female quality or aggression. The relationship between male and female parental effort is an important question for the evolution of mating systems and parental care and has been examined in a number of species (e.g., [24-29]). However, few studies have examined the relationship between female aggression and male quality or paternal care, all of which could alter the social pair's reproductive success.

The dark-eyed junco (Junco hyemalis carolinensis) is a well-studied model for understanding interactions between the sexes and phenotype in free-living animals [29-35]. Junco females vary in their level of same-sex aggression and maternal care $[3,11,21,36-41]$. Aggressive females spend less time brooding and in some years produce smaller eggs, but provision more frequently [11]. Further, in some years, aggressive females experience greater nest success, while in other years there is no relationship between aggression and nest success $[3,11]$. Here, I examine the relationship between female-female aggression during the incubation period and measures of male quality and then examine the relationships between male and female parental behavior during the early nestling period. I use this data to address two questions: (1) what is the relationship between female aggression and mate phenotype, that is, are aggressive females more often mated to high or low quality males, (2) do the relationships between male and female paternal care suggest that males mated to low care females might compensate by increasing their own level of effort? If aggression is a tool used in female-female competition for high quality mates, or if males prefer aggressive females, we predict a positive relationship between aggression and measures of male quality. Similarly, if females are competing for more parental males, or if males increase care when mated to competitive females, we predict a positive relationship between female aggression and male parental behavior. However, if females are competing primarily for access to high quality territories or nest sites, a relationship between female behavior and mate quality or care is not predicted. Finally, if males adjust their behavior to compensate for reduced female care or that females adjust to male care, we expect a negative relationship between male and female parental care measures. While if the sexes do not adjust according their mate's efforts, we would expect no relationship between male and female efforts.

\section{Methods}

2.1. Study Species, Site, and General Methods. This study took place on and around Mountain Lake Biological Station in Giles Co., Virginia $\left(37^{\circ} 22^{\prime} \mathrm{N}, 80^{\circ} 32^{\prime} \mathrm{W}\right)$ USA, from April 15 to August 10 2008-2010. Dark-eyed juncos are a mildly dimorphic (size and coloration), socially monogamous songbird with biparental care; females build the nest, incubate, brood, feed nestlings, and defend the nest from predators; males assist in feeding and nest defense [42]. This population has been the focus on many previous studies, and details regarding the study site, species, and general practices are available elsewhere $[41,43,44]$. Briefly, all known residents were captured using a combination of baited mist nets and Potter traps. Individuals were banded with serially numbered metal bands and a unique combination of color bands for individual identification in the field. Birds were aged using a combination of mark-recapture data and plumage and eye coloration [42]; birds were classified as first year or after first year breeders. From April 15th of both years, territories were searched daily in an effort to locate all nesting attempts. Once a nest was located, the social pair was identified, and the nest was monitored throughout the nesting cycle on a regular schedule; for details see $[3,43,44]$. A portion of data used in this analysis was collected as part of a larger project examining the relationships between female behaviors, reproductive success, and hormone levels, which are presented elsewhere [3, 11, 41, 45]. However, the data have not been examined in relation to male behavior or morphology.

2.2. Mate Size and Ornamentation. Body size was estimated using tarsus, wing, and tail length. Male ornamentation was estimated by quantifying individual differences in the amount tail-white each male displayed. Tail-white is important in courtship and aggressive interactions, and more tail-white is attractive to females [43, 46-48]. Further, previous research in this population has shown that male body size is positively correlated with tail-white and that large males with more tailwhite sired offspring with more females [43]. Because many individuals were measured multiple times in the same year, I selected the measurements taken by the most senior observer [43]. In the event that there were multiple observations, I took the mean. Both wing and tail tend to increase between the first and second year of breeding [42] and were positively correlated $\left(R^{2}=0.31, n=62, P<0.001\right)$. However, because wing length and tail length respond to different selective pressures [30, 43, 49], I examined their relationship with female behavior separately to capture more of the potentially important variance.

2.3. Aggression Towards A Same-Sex Intruder. Female aggression was quantified using a previously established and standardized behavioral assay [3, 45]. Previous research has shown that female responses are consistent across contexts 
and nesting attempts [45]. Further, this behavioral measure is related to egg size, hatchling mass, provisioning, brooding, and nest defense and is positively related to nest success in some years $[3,11,45]$. This suggests that female response to a simulated intruder is an ecologically relevant behavior with implications for female fitness. Aggression towards an intruder was assayed during the incubation period, which in past research produced the most reliable and robust responses [45] (Reichard pers comm). In brief, the behavioral assay consists of a same-sex conspecific being placed in a small wire cage with large openings permitting a clear view, positioned 1-3 $\mathrm{m}$ from the focal female's nest, while the female was absent and covered by a camouflage-patterned cloth. The trial began when the female returned to within $5 \mathrm{~m}$ of the nest and the lure was uncovered. The lure used for a trial was randomly assigned from a group of females captured offsite and held throughout the season (five per year); lure identity had no effect on female response $(P>0.25)$. Observations were made by a single observer 10-20 $\mathrm{m}$ away using binoculars. Behaviors recorded include the amount of time spent within $0.25 \mathrm{~m}, 1 \mathrm{~m}$, and $5 \mathrm{~m}$, the number of dives (swoops at the cage without contact), and hits (actual contacts with the cage). All trials were conducted from 0700 to 1100 , from 15 May to 15 July for all years. Previous research has shown that the amount of time spent within $0.25 \mathrm{~m}$ is strongly predictive of the number of attacks $[3,11]$; so we use that measure in these analyses. Trials were $10 \mathrm{~min}$ long and included 69 focal females $(2008 n=38,2009 n=17$, and $2010 n=14)$. To improve normality, time within $0.25 \mathrm{~m}$ was square root transformed; transformed values were used as a measure of female competitive behavior (aggression score). Only one female was assayed in more than one year, minimizing the possibility of pseudoreplication.

2.4. Parental Behavior. We quantified parental behavior in 2009 and 2010 by videotaping each nest for $4 \mathrm{~h}$ between 0900 and 1700 on day 3 after hatching. The camera was placed 2-4 $\mathrm{m}$ from the nest. Recordings were later analyzed by a single observer to quantify the number of feeding trips, the identity of the feeding parent, the number of brooding bouts, and the length of each brooding bout. I used these data to calculate the number of provisioning trips per nestling per hour and the average amount of time the female spent brooding (minutes). Neither female's age nor year had an effect on female brooding or provisioning, or male provisioning behavior (all $P>0.25$ ). However, date showed strong trends with both measures and was included in final models. Descriptive statistics are reported in Table 1.

2.5. Statistical Analysis. To condense the observed variation into male morphology measurements I used principal components analysis. Of 62 focal males in the total data set, only two occurred in two years and another in all three years, excluding these males from subsequent years who had no qualitative effect on the reported relationships. To determine whether there was a relationship between female aggression and male quality I used multiple regression analysis with female aggression score as the dependent variable and estimates of male quality (size measures, ornamentation scores, principal component scores for quality, and provisioning rates) as potential predictors. To determine whether there was a relationship between male and female parental care measures I used multiple regression with male provisioning as the dependent variable and year, date, time of day, ambient temperature and female provisioning rates, or brooding behavior as predictive variables. I then used forward stepwise regression to select the final model (probability to enter, $P<0.25$; probability to leave, $P>0.10$ ). Only final models are presented. For illustration of the relationship between male and female provisioning, individual leverage effect pairs from leverage plots were calculated. Leverage plots are akin to partial correlations, showing the relationship between the variables of interested after controlling for variance from other factors in the model, and are made up of the actual residual from the best-fit line and the residual error without the effect in the model [50].

\section{Results}

3.1. Principal Component Analysis for Male Phenotype. In the PCA analysis for measure of male quality, two PC scores had an eigenvalue over 1 and were retained for further analysis. The first PC loaded positively on wing length and tail length, while the second component loaded positively on the amount of tail-white and negatively on tarsus length. Thus a high PC1 score indicates a male with long wing and tail measurements; a high PC2 score indicates a male with relatively more tailwhite and a shorter tarsus, after controlling for differences in wing length and tail length. Together the two variables captured $68 \%$ of the total variance in male measures (see Table 2). Descriptive statistics are reported in Table 1.

3.2. Female Aggression and Male Phenotype. Female aggressive behavior was unrelated to female age, presence of the male, time of day, ambient temperature, day of incubation, the number of eggs, date, or year (all $P>0.40$ ). Descriptive statistics are reported in Table 1. Female aggressive behavior was also unrelated to mate's age, either when classifying males as first year breeders or after first year breeders $(n=62$, aggression score, $t$-ratio $=-0.70, P=0.49$ ) or when assessing age as years $\left(n=62, R^{2}<0.01, P=0.91\right)$. There was no detectable relationship between female aggressive behavior and male mass $(r=0.01, P=0.9)$, wing $(r=0.01, P=0.9)$, tail $(r=-0.06, P=0.6)$, tarsus length $(r=0.04, P=$ $0.8)$, or any age $\times$ morphology interaction $(n=61$, all $P>$ $0.25)$. Female aggression was not related to either principal component summarizing male quality (Figure $1 ; n=61, \mathrm{PC} 1$, $r=-0.01, P=0.9$; PC2, $r=-0.07, P=0.6)$. Finally, there was no detectable relationship between female aggressive behavior and male parental care (provisioning rate) (Figure 1; $r=0.14, P=0)$.

3.3. Female and Male Care. There was a strong negative relationship between male and female feeding behaviors in the final model, which included day of the year and year 
TABLE 1: Descriptive statistics for female behaviors and male quality measure (morphology and behavior).

\begin{tabular}{|c|c|c|c|c|c|}
\hline Class of trait & Behavior & Mean & $\pm \mathrm{SE}$ & Range & Sample size \\
\hline \multirow{3}{*}{ Female aggression } & Time within $1 / 4 \mathrm{~m}$ (sec) & 137 & 17.9 & $0-579 \mathrm{~s}$ & 69 \\
\hline & Hits & 6.6 & 1.5 & $0-55$ & 69 \\
\hline & Dives & 0.91 & 0.3 & $0-15$ & 69 \\
\hline \multirow{2}{*}{ Female parental care } & Average brood bout (min) & 13.0 & 7.3 & $4.1-33.8$ & 28 \\
\hline & $\begin{array}{c}\text { Provisioning rate } \\
\text { (feeds/nestling/hour) }\end{array}$ & 0.96 & 0.07 & $0.26-1.7$ & 28 \\
\hline \multirow{5}{*}{ Male quality measures } & Wing $(\mathrm{mm})$ & 82.7 & 0.2 & $79.8-88$ & 62 \\
\hline & Tail (mm) & 71.2 & 0.3 & $67.4-77$ & 62 \\
\hline & Tarsus (mm) & 21.8 & 0.07 & $20.4-22.8$ & 62 \\
\hline & Tail-white score & 2.30 & 0.05 & $1.5-3.15$ & 61 \\
\hline & Age (years) & 2.74 & 0.3 & $1-6$ & 62 \\
\hline Male parental care & $\begin{array}{c}\text { Provisioning rate } \\
\text { (feeds/nestling/hour) }\end{array}$ & 0.92 & 0.08 & $0-1.625$ & 28 \\
\hline
\end{tabular}

TABLE 2: Results of the principal component analysis (PCA) for estimates of male quality. Shown are the loadings for the first two principal components. Tail-white is an estimate of ornamentation, referring to the amount of white on the outer retrices (tail feathers).

\begin{tabular}{lcc}
\hline Measure & Prin1 & Prin2 \\
\hline Wing chord & 0.89 & 0.04 \\
Tail length & 0.83 & 0.34 \\
Tarsus length & 0.37 & -0.61 \\
Tail-white & -0.15 & 0.61 \\
Eigenvalue & $\mathbf{1 . 6 3}$ & $\mathbf{1 . 0 9}$ \\
Percent of variance explained & $\mathbf{4 1 \%}$ & $\mathbf{2 7 \%}$ \\
\hline
\end{tabular}

(Figure 2; male feeding adj. $R^{2}=0.30, F_{3,28}=4.78, P=$ 0.0094 , year $b=-0.04, P=0.0200$, day of year $b=-0.0003$, $P=0.015$, and female feeding $b=-0.506, P=0.016)$. There was no detectable relationship between the average amount of time a female spends brooding or her first brooding bout and how frequently her mate provisioned (Av brood, $n=28$, $R^{2}=0.009, P=0.6$, 1st brood $\left.R^{2}=0.30, P=0.4\right)$. One social pair exhibited high male provisioning and high female brooding (upper right corner Figure 2(b)), while the trend was generally negative. When this pair is excluded, there was a negative trend between male provisioning and the average amount of time a female spends brooding (Av brood, $n=27$, $R^{2}=0.11, P=0.0980,1$ st brood $\left.R^{2}=0.02, P=0.5\right)$.

\section{Discussion}

4.1. Female Aggression Is Unrelated to Mate Quality and Care. Overall, it appears that for junco females, male quality may be a secondary consideration after nest site quality. Examining three years of behavioral data and social pairings, I found no evidence for a relationship between female aggression and any of our measures of male quality (age, size, or ornamentation). These results do not support the hypothesis that males are discriminating among females based on their levels of aggression. Further, these results do not support the hypothesis that female-female competition is driven by mate competition in this species. Similarly, over two breeding seasons there was no detectable relationship between female aggression during incubation and male provisioning rates during the early nestling period. This suggests that females are unlikely to be competing with other females, directly or indirectly, for males that invest more in paternal care. It also indicates that males mated to aggressive females are not investing more heavily in those offspring, at least not via provisioning. Thus, it appears to be more likely that junco females are competing for an ecological resource that is limited or varies in quality, rather than competing for a high quality mate. Nest failure in juncos is primarily due to predation by small mammals [51]. Therefore, it seems likely that females are competing for access to high quality territories or nest sites, for example, those with fewer predators, reduced density, greater food availability, or more protected nest sites $[3,11]$. If this is a general pattern, then positive relationship a between male quality and female phenotypes may be a by-product of female competition, rather than the primary mechanism driving female competition [52].

Importantly, this is a correlative study on free-living animals. I cannot exclude the possibility that there is male preference for female behavioral phenotype or that females do compete for a high quality or paternal males. Mate choice in the field is complicated and likely results in compromises; individuals may be forced to optimize based on limited information. For instance, males may prefer aggressive females, but because of limited time and competition may profit more from selecting quickly. Similarly, females likely have a preference for male quality [51] and may change partners given the opportunity [53] but rarely have a chance to sample the entire population before choosing a mate. This study also focused on social pairings; however, mate genetic quality may be more important when assessing potential extra-pair partners. This is unlikely to explain the positive relationship 


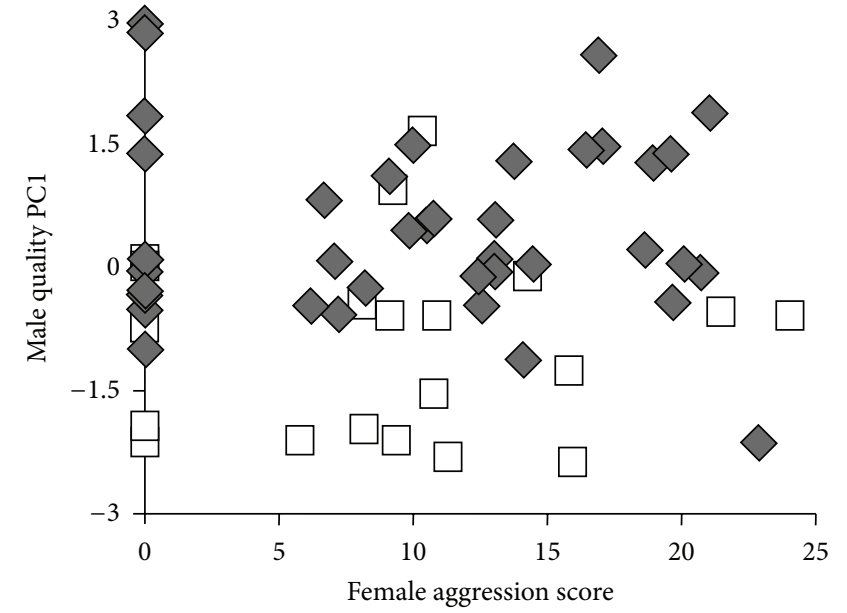

(a)

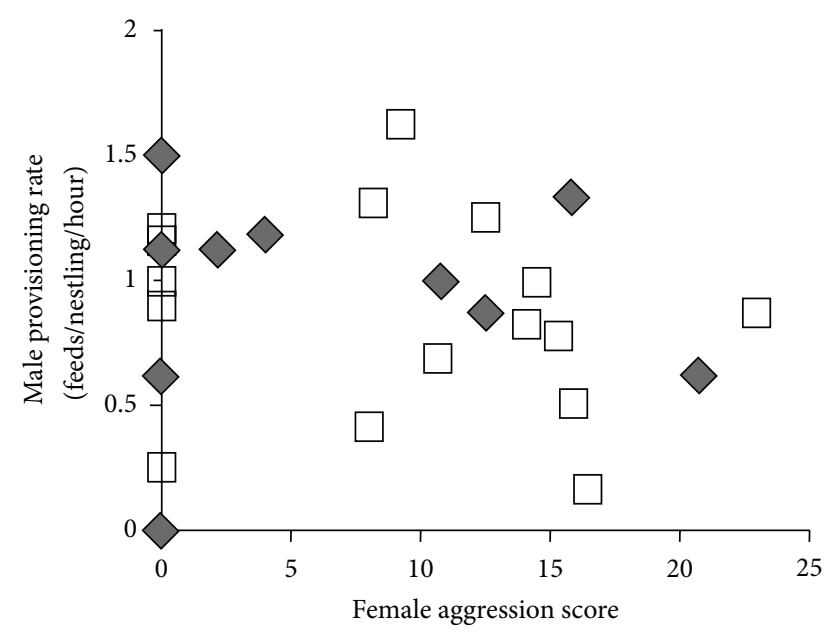

(b)

FIGURE 1: Scatterplot illustrating the lack of relationship between female aggression and the first principal component for male quality (a) and between female aggression and male provisioning rate (b); $P>0.25$ in both cases. Open squares denote males that are past their first breeding year; grey diamonds are first year breeding males.

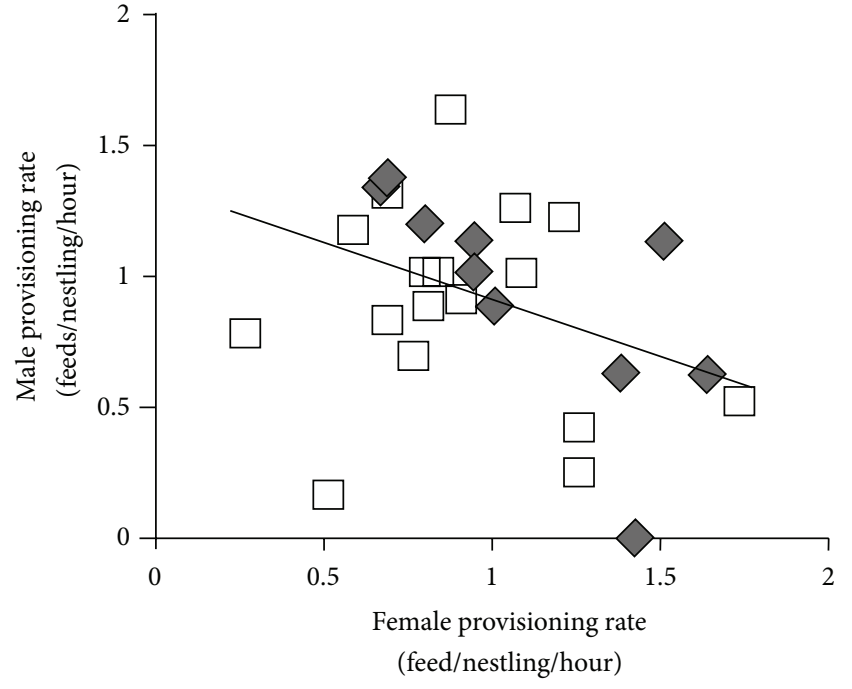

(a)

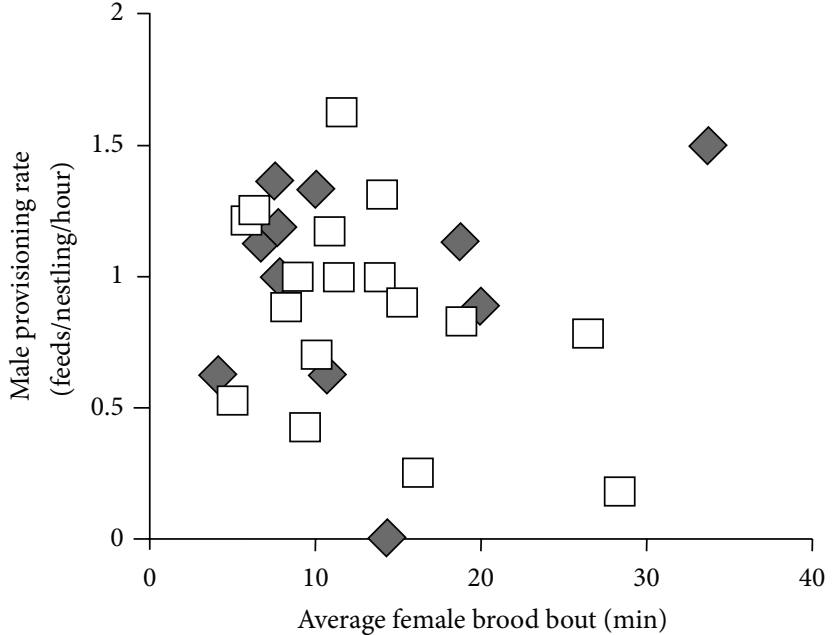

(b)

FIGURE 2: Scatter plots illustrating the relationships between male and female parental behaviors. In (a), the negative relationship between female and male provisioning rates, $P=0.009$ (a). Points are leverage plot pairs (see Section 2.5) showing the relationship between variables controlling for other predictors in the model, akin to a partial correlation. (b) Illustrates the lack of relationship between female brooding behavior and male provisioning rate. Grey diamonds denote first year breeding males; open squares denote males past their first breeding year.

between female reproductive success and aggression; females are unlikely be limited by their access to their preferred genetic mate but may reduce the benefits received from competing for a high quality social mate.

Instead, it seems that male quality may be a secondary consideration after nest site quality. This possibility is supported by previous experimental studies of juncos, which showed that when males were removed completely, some single females successfully raised an entire brood with no assistance, while others failed repeatedly [54], suggesting that nest success can be independent of male quality and may depend more on female behavior or territory quality, which was not measured in this study. Together, these considerations suggest that male quality is less important than predation risk. Finally, it is also important to note that male parental care was estimated on day 3 , consistent with previous work in this species $[55,56]$. Nestlings at that stage are quite small and food demands are lower, and therefore male care at this stage may not be representative, so caution is warranted in interpreting the relationship with male care. 
However, two separate studies in house sparrows (Passer domesticus) have found that male parental behavior is highly repeatable between and within years $[57,58]$, suggesting that the relative degree of male effort is unlikely to change to a large degree in the course of a single nesting attempt.

4.2. Female and Male Offspring Care. We found a strong negative relationship between female and male provisioning; that is, males that provisioned most were paired with females that provisioned least. This is counter to previous research in juncos that found positive covariation between male and female provisioning behavior [56]. This inconsistent pattern is reflected in numerous studies across a range of species. In addition to juncos, a positive association between male and female feeding rates has been reported in barn swallows (Hirundo rustica) [59] and yellow warblers (Dendroica petechia) [60], and experimentally increasing partner visit rates led to an increase in focal individual visits in great tits (Parus major) [61]. However, in some species no relationship between male and females provisioning behaviors has been detected, as in Gouldian finch (Erythrura gouldiae) [62] and blue tits (Cyanistes caeruleus) [63]. While in house wrens (Troglodytes aedon) [64], tree swallows (Hirundo rustica), and in this study, the relationship is negative. Further, in some species, the relationship depends on the combination of partner phenotypes, such as in white-throated sparrows (Zonotrichia albicollis), which have two morphs that differ in aggression and parental care; there was no relationship between white-striped males paired with tan females, but there was a positive trend when tan males pair with white females [65]. Finally, in some species the relationship appears to be plastic. For instance, in willow tits (Parus montanus), there was a positive relationship early in the nestling period, but this relationship tended towards negative at the end of the nestling period [66]. Further, in dunnocks (Prunella modularis), there was no relationships between male and female provisioning rates in unmanipulated pairs/trios, but both female and beta-male provisioning rates increased when investment by others in the pair/group was experimentally reduced [25].

Why species with similar mating systems vary so much in the nature of the relationship between male and female parental care, and, more specifically, why the relationship between male and female provisioning effort in juncos would correlate positively in some years, but negatively in other years, is unclear. The way that partners negotiate and adjust their efforts is still an open question, and the inconsistent and variable nature of the patterns observed across species suggests they are likely quite complicated and plastic. Because this study was correlative, it is unclear whether (a) females were adjusting to male care levels, (b) male were adjusting to female care, or (c) some combination of the two. Female juncos mated to males with experimentally elevated testosterone, which reduces male care, provision more often than females mated to control males, suggesting that females compensate for the lack of male care [67]. However, captive females in breeding condition also find $\mathrm{T}$ males more attractive [68]; thus the increased female feeding rates may be due to females investing more in the offspring of males they perceive to be high quality (i.e., sexy son hypothesis), rather than in response to reduced care per se [61]. Similarly, females treated with testosterone also tended to feed less frequently, though the difference was not significant, and males mated to $\mathrm{T}$ females fed nestlings at a higher rate than males mated to $\mathrm{C}$ females, suggesting males may also compensate [36]. It is also important to note that the behaviors measured here are but a small part of the total way that males and females may invest in offspring, and examining other efforts would shed further light on parental investment decision-making.

\section{Conclusion}

These results, together with previous research showing that females can be successful without a mate [54], suggest that male assistance may buffer variation in female parental quality but is not essential for success. It appears that, for junco females, territory or nest site quality is a more primary concern than mate quality. Furthermore, these results raise the possibility that positive relationships between female trait expression and mate quality may be a side product of female competition for high quality territories, which may be disproportionally controlled by high quality males.

\section{Conflict of Interests}

The author declares that there is no conflict of interests regarding the publication of this paper.

\section{Acknowledgments}

Research was supported by a National Science Foundation (NSF) Doctoral Dissertation Improvement Grant (0910036) and an NSF Graduate Research Fellowship (GRFP). This research adhered to the Association for the Study of Animal Behavior/Animal Behavior Society Guidelines for the use of animals in research and the legal requirements of the United States of America (USFWS special use permit no. MB093279-2, USGS banding permit number 20261), the states of Indiana and Virginia, and was conducted in compliance with the University of Virginia and Indiana University Institutional Animal Care and Use Committee (protocol \#09037). The author thanks E.D. Ketterson for years of support and guidance; S. Wanamaker, A. Dapper, M. Rich, and M. Forquer for assistance with data collection; the Ketterson Lab, C. Ziegenfus, and the United Junco Workers for the field assistance; S. Hoobler for additional support; and Mountain Lake Biological Station (B. Brodie III, Director, and E. Nagy, Associate Director), and Mountain Lake Hotel for permission to work on their property.

\section{References}

[1] M. J. West-Eberhard, "Sexual selection, social competition, and speciation," Quarterly Review of Biology, vol. 58, no. 2, pp. 155183, 1983. 
[2] J. A. Tobias, R. Montgomerie, and B. E. Lyon, "The evolution of female ornaments and weaponry: social selection, sexual selection and ecological competition," Philosophical Transactions of the Royal Society B: Biological Sciences, vol. 367, no. 1600, pp. 2274-2293, 2012.

[3] K. E. Cain and E. D. Ketterson, "Competitive females are successful females; phenotype, mechanism, and selection in a common songbird," Behavioral Ecology and Sociobiology, vol. 66, no. 2, pp. 241-252, 2012.

[4] K. A. Rosvall, "Intrasexual competition in females: evidence for sexual selection?” Behavioral Ecology, vol. 22, no. 6, pp. 11311140, 2011.

[5] T. H. Clutton-Brock, "Sexual selection in females," Animal Behaviour, vol. 77, no. 1, pp. 3-11, 2009.

[6] P. Stockley and J. Bro-Jørgensen, "Female competition and its evolutionary consequences in mammals," Biological Reviews, vol. 86, no. 2, pp. 341-366, 2011.

[7] T. H. Clutton-Brock and E. Huchard, "Social competition and selection in males and females," Philosophical Transactions of the Royal Society B, vol. 368, no. 1631, Article ID 20130074, 2013.

[8] K. A. Rosvall, "Cost of female intrasexual aggression in terms of offspring quality: a cross-fostering study," Ethology, vol. 117, no. 4, pp. 332-344, 2011.

[9] K. A. Rosvall, "Life history trade-offs and behavioral sensitivity to testosterone: an experimental test when female aggression and maternal care co-occur," PLoS ONE, vol. 8, no. 1, Article ID e54120, 2013.

[10] B. Dantzer, A. G. McAdam, R. Palme, M. M. Humphries, S. Boutin, and R. Boonstra, "Maternal androgens and behaviour in free-ranging North American red squirrels," Animal Behaviour, vol. 81, no. 2, pp. 469-479, 2011.

[11] K. E. Cain and E. D. Ketterson, "Costs and benefits of competitive traits in females: aggression, maternal care and reproductive success," PLoS ONE, vol. 8, Article ID e77816, 2013.

[12] C. Packer, D. A. Collins, A. Sindimwo, and J. Goodall, "Reproductive constraints on aggressive competition in female baboons," Nature, vol. 373, no. 6509, pp. 60-63, 1995.

[13] M. J. Nelson-Flower, P. A. R. Hockey, C. O'Ryan et al., "Costly reproductive competition between females in a monogamous cooperatively breeding bird," Proceedings of the Royal Society B: Biological Sciences, vol. 280, no. 1762, Article ID 20130728, 2013.

[14] T. Slagsvold and J. T. Lifjeld, "Polygyny in birds: the role of competition between females for male parental care," American Naturalist, vol. 143, no. 1, pp. 59-94, 1994.

[15] K. A. Rosvall, "Sexual selection on aggressiveness in females: evidence from an experimental test with tree swallows," Animal Behaviour, vol. 75, no. 5, pp. 1603-1610, 2008.

[16] J. C. Beehner, J. E. Phillips-Conroy, and P. L. Whitten, "Female testosterone, dominance rank, and aggression in an Ethiopian population of hybrid baboons," American Journal of Primatology, vol. 67, no. 1, pp. 101-119, 2005.

[17] S. R. Pryke, "Fiery red heads: female dominance among head color morphs in the Gouldian finch," Behavioral Ecology, vol. 18, no. 3, pp. 621-627, 2007.

[18] K. Yasukawa and W. A. Searcy, "Aggression in female RedWinged Blackbirds: a strategy to ensure male parental investment," Behavioral Ecology and Sociobiology, vol. 11, no. 1, pp. 13$17,1982$.

[19] T. Slagsvold, "Female-female aggression and monogamy in great tits Parus major," Ornis Scandinavica, vol. 24, no. 2, pp. 155-158, 1993.
[20] M. I. Sandell, "Female aggression and the maintenance of monogamy: Female behaviour predicts male mating status in European starlings," Proceedings of the Royal Society B: Biological Sciences, vol. 265, no. 1403, pp. 1307-1311, 1998.

[21] J. M. Jawor, R. Young, and E. D. Ketterson, "Females competing to reproduce: dominance matters but testosterone may not," Hormones and Behavior, vol. 49, no. 3, pp. 362-368, 2006.

[22] K. A. Rosvall, "Do males offset the cost of female aggression? An experimental test in a biparental songbird," Behavioral Ecology, vol. 21, no. 1, pp. 161-168, 2010.

[23] R. W. Knapton and J. B. Falls, "Differences in parental contribution among pair types in the polymorphic white-throated sparrow," Canadian Journal of Zoology, vol. 61, no. 6, pp. 12881292, 1983.

[24] N. Burley, "Parental investment, mate choice, and mate quality," Proceedings of the National Academy of Sciences of the United States of America, vol. 74, no. 8, pp. 3476-3479, 1977.

[25] B. J. Hatchwell and N. B. Davies, "Provisioning of nestlings by dunnocks, Prunella modularis, in pairs and trios compensation reactions by males and females," Behavioral Ecology and Sociobiology, vol. 27, no. 3, pp. 199-209, 1990.

[26] M. J. L. Magrath and J. Komdeur, "Is male care compromised by additional mating opportunity?" Trends in Ecology \& Evolution, vol. 18, no. 8, pp. 424-430, 2003.

[27] L. Wolf, E. D. Ketterson, and V. Nolan, "Female condition and delayed benefits to males that provide parental care: a removal study," The Auk, vol. 108, no. 2, pp. 371-380, 1991.

[28] P. O. Dunn and A. Cockburn, "Evolution of male parental care in a bird with almost complete cuckoldry," Evolution, vol. 50, no. 6, pp. 2542-2548, 1996.

[29] E. D. Ketterson and V. Nolan Jnr, "Male parental behavior in birds," Annual Review of Ecology and Systematics, vol. 25, pp. 601-628, 1994.

[30] K. E. Cain, C. M. Bergeon Burns, and E. D. Ketterson, “Testosterone production, sexually dimorphic morphology, and digit ratio in the dark-eyed junco," Behavioral Ecology, vol. 24, no. 2, pp. 462-469, 2013.

[31] E. D. Ketterson and V. Nolan Jr., "Adaptation, exaptation, and constraint: a hormonal perspective," The American Naturalist, vol. 154, pp. S4-S25, 1999.

[32] R. L. Holberton, T. Boswell, and M. J. Hunter, "Circulating prolactin and corticosterone concentrations during the development of migratory condition in the Dark-eyed Junco, Junco hyemalis," General and Comparative Endocrinology, vol. 155, no. 3, pp. 641-649, 2008.

[33] J. M. Casto, J. Nolan V., and E. D. Ketterson, "Steroid hormones and immune function: experimental studies in wild and captive dark-eyed juncos (Junco hyemalis)," American Naturalist, vol. 157, no. 4, pp. 408-420, 2001.

[34] P. Deviche, C. Breuner, and M. Orchinik, "Testosterone, corticosterone, and photoperiod interact to regulate plasma levels of binding globulin and free steroid hormone in Dark-eyed Juncos, Junco hyemalis," General and Comparative Endocrinology, vol. 122, no. 1, pp. 67-77, 2001.

[35] D. G. Reichard and E. D. Ketterson, "Estimation of female home-range size during the nestling period of dark-eyed juncos," The Wilson Journal of Ornithology, vol. 124, no. 3, pp. 614620, 2012.

[36] D. M. O’Neal, D. G. Reichard, K. Pavilis, and E. D. Ketterson, "Experimentally-elevated testosterone, female parental care, and reproductive success in a songbird, the Dark-eyed Junco 
(Junco hyemalis)," Hormones and Behavior, vol. 54, no. 4, pp. 571-578, 2008.

[37] E. D. Ketterson, "Aggressive behavior in wintering Dark-eyed Juncos: determinants of dominance and their possible relation to geographic variation in sex ratio," The Wilson Bulletin, pp. 371-383, 1979.

[38] E. D. Clotfelter, D. M. O’Neal, J. M. Gaudioso et al., "Consequences of elevating plasma testosterone in females of a socially monogamous songbird: Evidence of constraints on male evolution?" Hormones and Behavior, vol. 46, no. 2, pp. 171178, 2004.

[39] D. A. Zysling, T. J. Greives, C. W. Breuner, J. M. Casto, G. E. Demas, and E. D. Ketterson, "Behavioral and physiological responses to experimentally elevated testosterone in female dark-eyed juncos (Junco hyemalis carolinensis)," Hormones and Behavior, vol. 50, no. 2, pp. 200-207, 2006.

[40] K. A. Rosvall, C. M. Bergeon Burns, J. Barske et al., "Neural sensitivity to sex steroids predicts individual differences in aggression: implications for behavioural evolution," Proceedings of the Royal Society B: Biological Sciences, vol. 279, no. 1742, pp. 3547-3555, 2012.

[41] K. E. Cain and E. D. Ketterson, "Individual variation in testosterone and parental care in a female songbird; the darkeyed junco (Junco hyemalis)," Hormones and Behavior, vol. 64, no. 4, pp. 685-692, 2013.

[42] V. Nolan, E. D. Ketterson, D. A. Cristol et al., Dark-Eyed Junco, Cornell Lab of Ornithology, Philadelphia, Pa, USA, 2002.

[43] J. W. McGlothlin, P. G. Parker, V. Nolan Jr., and E. D. Ketterson, "Correlational selection leads to genetic integration of body size and an attractive plumage trait in dark-eyed juncos," Evolution, vol. 59, no. 3, pp. 658-671, 2005.

[44] W. L. Reed, M. E. Clark, P. G. Parker et al., "Physiological effects on demography: a long-term experimental study of testosterone's effects on fitness," American Naturalist, vol. 167, no. 5, pp. 667-683, 2006.

[45] K. E. Cain, M. S. Rich, K. Ainsworth, and E. D. Ketterson, "Two sides of the same coin? Consistency in aggression to conspecifics and predators in a female songbird," Ethology, vol. 117, no. 9, pp. 786-795, 2011.

[46] M. H. Balph, "Winter social behaviour of dark-eyed juncos: communication, social organization, and ecological implications," Animal Behaviour, vol. 25, no. 4, pp. 859-884, 1977.

[47] R. L. Holberton, K. P. Able, and J. C. Wingfield, "Status signalling in dark-eyed juncos, Junco hyemails: plumage manipulations and hormonal correlates of dominance," Animal Behaviour, vol. 37, no. 4, pp. 681-689, 1989.

[48] J. W. McGlothlin, J. M. Jawor, T. J. Greives, J. M. Casto, J. L. Phillips, and E. D. Ketterson, "Hormones and honest signals: males with larger ornaments elevate testosterone more when challenged," Journal of Evolutionary Biology, vol. 21, no. 1, pp. 39-48, 2008.

[49] T. Székely, J. D. Reynolds, and J. Figuerola, "Sexual size dimorphism in shorebirds, gulls, and alcids: the influence of sexual and natural selection," Evolution, vol. 54, no. 4, pp. 1404-1413, 2000.

[50] J. Sall, "Leverage plots for general linear hypotheses," The American Statistician, vol. 44, no. 4, pp. 308-315, 1990.

[51] E. D. Clotfelter, A. B. Pedersen, J. A. Cranford et al., "Acorn mast drives long-term dynamics of rodent and songbird populations," Oecologia, vol. 154, no. 3, pp. 493-503, 2007.

[52] N. R. LeBas, "Female finery is not for males," Trends in Ecology and Evolution, vol. 21, no. 4, pp. 170-173, 2006.
[53] K. Otter and L. Ratcliffe, "Female initiated divorce in a monogamous songbird: abandoning mates for males of higher quality," Proceedings of the Royal Society B: Biological Sciences, vol. 263, no. 1368, pp. 351-355, 1996.

[54] L. Wolf, E. D. Ketterson, and V. Nolan Jr., "Paternal influence on growth and survival of dark-eyed junco young: do parental males benefit?" Animal Behaviour, vol. 36, no. 6, pp. 1601-1618, 1988.

[55] D. M. O'Neal, Considering the Roles of Climate Change, Winter Habitat, and Immune Function in a Differential Migrant, 2010.

[56] E. D. Clotfelter, C. Ray Chandler, V. Nolan Jr., and E. D. Ketterson, "The influence of exogenous testosterone on the dynamics of nestling provisioning in dark-eyed juncos," Ethology, vol. 113, no. 1, pp. 18-25, 2007.

[57] P. L. Schwagmeyer and D. W. Mock, "How consistently are good parents good parents? Repeatability of parental care in the house sparrow, Passer domesticus," Ethology, vol. 109, no. 4, pp. 303-313, 2003.

[58] S. Nakagawa, D. O. S. Gillespie, B. J. Hatchwell, and T. Burke, "Predictable males and unpredictable females: sex difference in repeatability of parental care in a wild bird population," Journal of Evolutionary Biology, vol. 20, no. 5, pp. 1674-1681, 2007.

[59] S. E. Maguire and R. J. Safran, "Morphological and genetic predictors of parental care in the North American barn swallow Hirundo rustica erythrogaster," Journal of Avian Biology, vol. 41, no. 1, pp. 74-82, 2010.

[60] M. V. Studd and R. J. Robertson, "Sexual selection and variation in reproductive strategy in male yellow warblers (Dendroica petechia)," Behavioral Ecology and Sociobiology, vol. 17, no. 2, pp. 101-109, 1985.

[61] C. A. Hinde, "Negotiation over offspring care?-a positive response to partner-provisioning rate in great tits," Behavioral Ecology, vol. 17, no. 1, pp. 6-12, 2006.

[62] S. R. Pryke and S. C. Griffith, "Socially mediated trade-offs between aggression and parental effort in competing color morphs," American Naturalist, vol. 174, no. 4, pp. 455-464, 2009.

[63] T. Limbourg, A. C. Mateman, and C. M. Lessells, "Parental care and UV coloration in blue tits: opposite correlations in males and females between provisioning rate and mate's coloration," Journal of Avian Biology, vol. 44, no. 1, pp. 17-26, 2013.

[64] M. L. Demory, C. F. Thompson, and S. K. Sakaluk, "Male quality influences male provisioning in house wrens independent of attractiveness," Behavioral Ecology, vol. 21, no. 6, pp. 1156-1164, 2010.

[65] J. G. Kopachena and J. B. Falls, "Re-evaluation of morph-specific variations in parental behavior of the white-throated sparrow," The Wilson Bulletin, vol. 105, pp. 48-59, 1993.

[66] S. Rytkönen, M. Orell, K. Koivula, and M. Soppela, "Correlation between two components of parental investment: nest defence intensity and nestling provisioning effort of willow tits," Oecologia, vol. 104, no. 3, pp. 386-393, 1995.

[67] E. D. Ketterson, V. Nolan Jr., L. Wolf, and C. Ziegenfus, "Testosterone and avian life histories: effects of experimentally elevated testosterone on behavior and correlates of fitness in the dark-eyed junco (Junco hyemalis)," American Naturalist, vol. 140, no. 6, pp. 980-999, 1992.

[68] D. A. Enstrom, E. D. Ketterson, and V. Nolan Jr., "Testosterone and mate choice in the dark-eyed junco," Animal Behaviour, vol. 54, no. 5, pp. 1135-1146, 1997. 

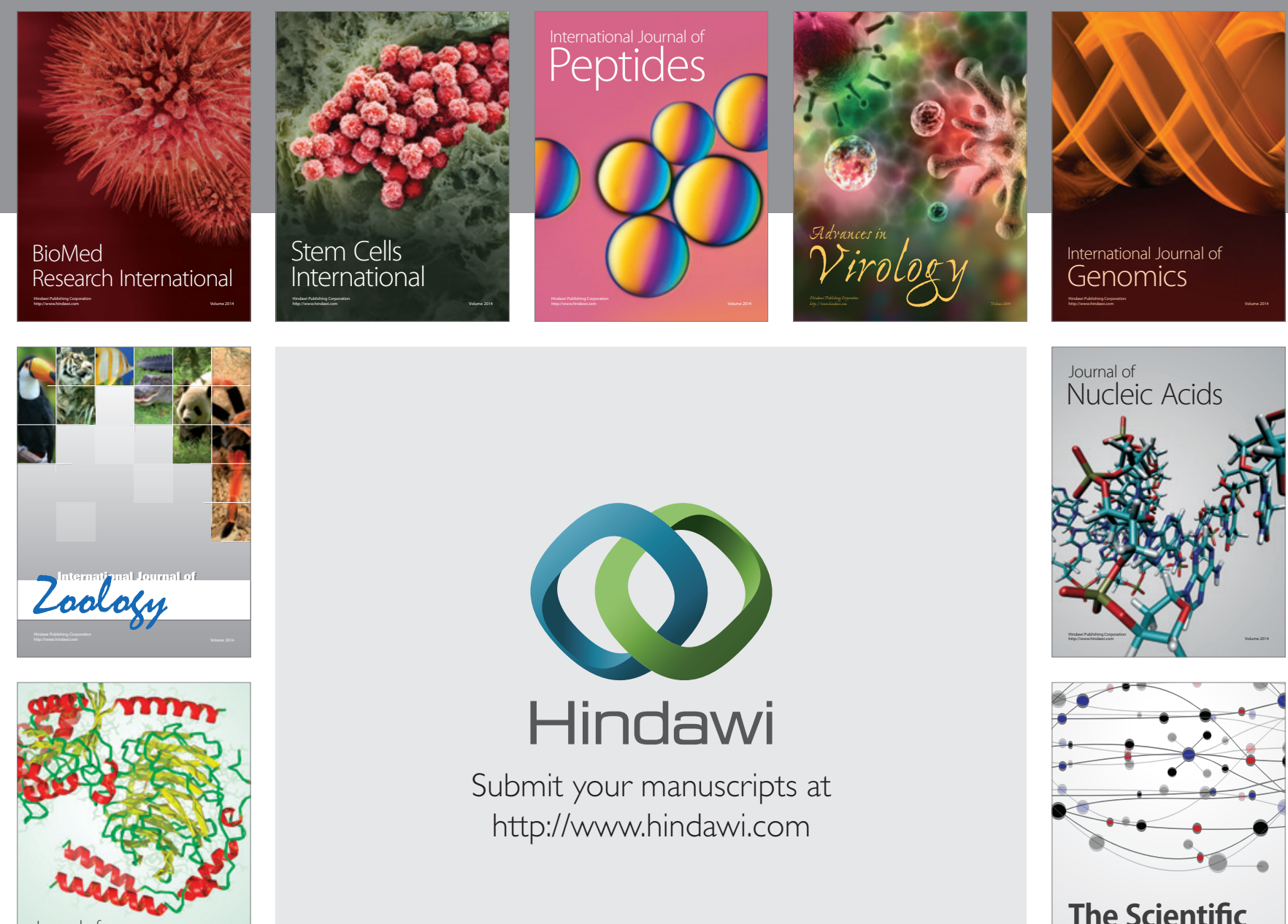

Submit your manuscripts at

http://www.hindawi.com

Journal of
Signal Transduction
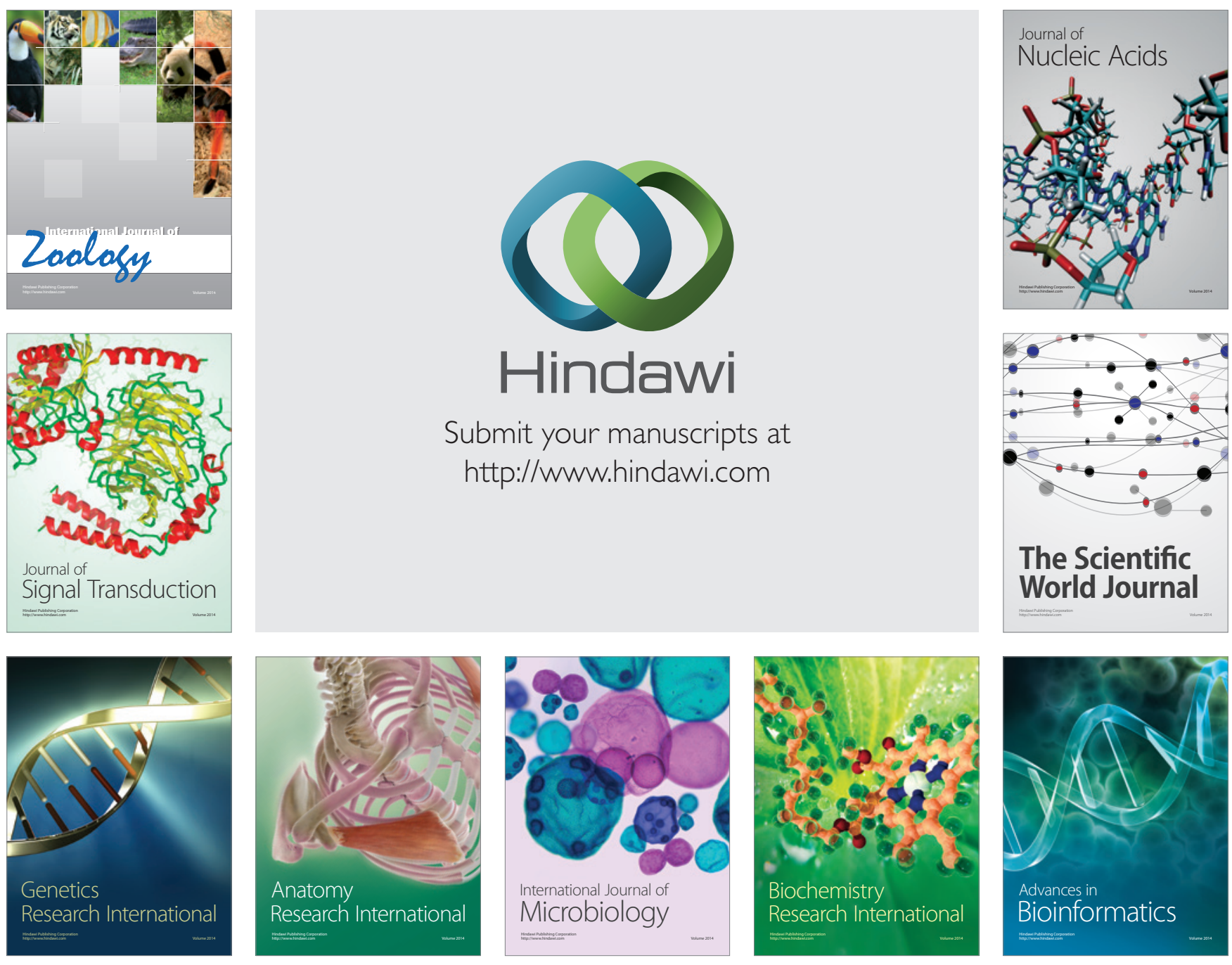

The Scientific World Journal
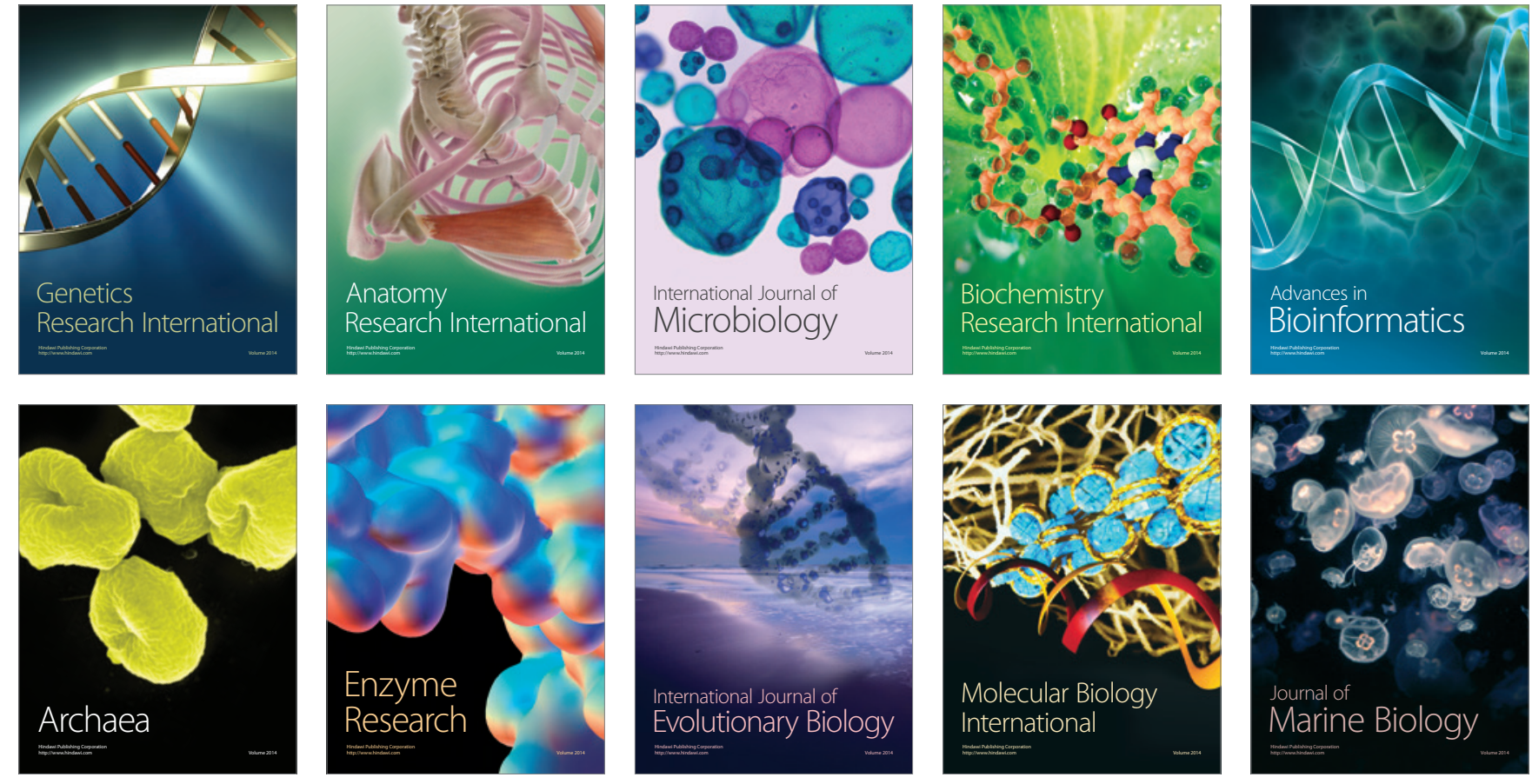